Mr. Linvecar. In this instance the patient was a gentleman, about thirty-eight years of age, suffering from phthisical symptoms; he was tall, and of spare habit of body. He had lately suffered much depression of spirits from some domestic calamity. On the night on which be died, he had walked home from the city with his wife, had eaten a light supper, and felt well. During the act of embracing his wife, he suddenly and instantly fell dead by her side. In this case the heart was healthy; there were tubercles in the lungs. Death had been produced by rupture of the basilary artery. There was an immense quantity of blood at the base of the brain. The second case had been seen by

Mr. Hutchinson. It was that of a gentleman, about 60 years of age, of full plethoric habit; he had been in the habit of meeting a female and accompanying her home. On one occasion, during the act of coition, he suddenly fell dead. In this case, also, the basilary artery was found ruptured: the death was in both cases instantaneous.

\section{MEDICAL RELIEF TO THE POOR.}

\section{To the Editor of The Lancet.}

SIR:-A renewal of the Poor-lawAct being about to engage the attention of Parliament, the clause relating to the medical provision for the sick poor will, of course, be open to revision. If the infamous system of tender should still be persisted in, will you allow me to suggest to you the expediency of putting up the lots, not in half-dozen districts, as heretofore, but singly, to use the Auctionmart phrase, to " suit the convenience of purchasers" (competitors).

The manifest impolicy of the present method is strikingly evidenced by what obtains in this neighbourhood; and $e x$ uno disce omnia. The sick poor of this township (St. Leonard's), with those of some halfdozen parishes annexed, are annually put up in one lot for medical competition; and that medico who shall be content with the lowest scale of remuneration, is officially installed in to the very honourable post. Now, it does not suit either of the resident practitioners of this town to compete for the aggregate lot, but they would willingly undertake the charge of the sick poor of the place, and possibly of one of the contiguous districts. This they are precluded from doing under the present odious system. The consequence is, that our sick poor are almost wholly provided for gratuitously by the medical residents, who voluntarily stand in the gap to remedy the very serious inconvenience to which the poor objects would be subjected in applying to the individual who is paid for such duty, but whose residence being in Hustings, is very rarely available in the hour of need. I would beg to suggest that the medical practitioner whose residence is the nearest to each particular district, shall, cateris paribus, have the option of performing its duties on such terms as have hitherto been assigned, or may hereafter be deemed adequate.

This objectionable feature of the present system admitting of easy adjustment, and being fraught with very serious evils, will, I feel assured, not be lightly passed over by so zealous an adrocate in the cause of medical and general reform as yourself; and I have the honour to be, Sir, your most obedient servant,

$$
\text { St. Leonard's-on-Sea, Feb. 7, } 1841 \text {. }
$$

VACcination.-From the account of one of the medical officers of the Hertford union, it appears that he had vaccinated 440 chil. dren, for which he received 1s. 6d. per head. Another of the medical officers had vaccinated 309 children, during the past quarter, for which he declined to receive any remuneration, preferring to do it gratis than to receive 1s. 6d. per bead, which he thought an inadequate remuneration.-Essex Mercury, April 12.

\section{TO CORRESPONDENTS.}

$M . R$. C. S. He is legally entitled to a fair remuneration, but to no specific sum settled by law. The character in which he is consulted on the occasion, does not either advance or reduce the amount of his claim. The charges for time and travelling are regulated always by circumstances, and vary accordingly.

A Nine Years' Subscriber shonld have a verdict in his favour. He is legally qualified, under the licence, to practise in any part of England and Wales.

Communications have been received from Mr. Howard ; Dr. West; Mr. Hiley; Mr. Allison; Alpha; A Seceder; Dr. Stewart; Mr. Curtis.

We have been unable to find room for $M r$. Braid's paper this week; it shall appear in our next.

We are obliged to postpone Sir Charles Scudamore's communication until next week, for want of space.

Will our correspondent from Helston send us an account of the case to which he alludes. The condition of which he speaks must be a symptom of a disease, and not the disease itself.

We are unable to find room for Mr. Semple's cases this week; they shall appear in an early number.

The reports of the London Medical Society and of the Westminster Medical Society are deferred until next week, for want of space. 